\title{
The Application of Flipped Classroom Model in the Course of "Japanese Translation"
}

\author{
Yan Xiaobi \\ Chengdu Neusoft University, Chengdu, Sichuan Province, 611844
}

Keywords: flipped classroom; teaching mode; Japanese translation; application

\begin{abstract}
Incorporating new information technology into the flipped classroom can effectively transform the roles of teachers and students, and accomplish the transference and the internalization process of knowledge in students. Thus, it can help improve the teaching quality of Japanese translation courses. However, there are still some problems in the preliminary exploration, which need to be corrected and improved in a timely manner. This paper analyzes the application of flipped classroom in the course of "Japanese translation”.

In recent years, with the acceleration of the internationalization process, Japanese has become one of the international languages as well as Chinese and English. China and Japan are very frequent in cooperation and communication and need more Japanese talents. As far as Japanese translation is concerned, this is a very important part of Japanese teaching. In addition, China attaches great importance to students' application of professional knowledge in the cultivation of talents. In Japanese teaching and learning, it is also the case that the translation can be used to investigate the application ability of Japanese-majored students. However, some schools have neglected the importance of Japanese translation, and the ability of the students to translate is crucial to their future development, so it is very necessary to improve the level of translation of students themselves.
\end{abstract}

\section{Current Situation of the Teaching of "Japanese Translation"}

In terms of the flipped classroom teaching model, many Japanese teachers do not attach importance to it. In their teaching process of translation, they mainly use previous ideas and methods, focusing on the explanation of the textbooks. In the classroom teaching, some teachers talk blindly, ignoring the students' own feelings and receptivity. Most schools pay more attention to the vocabulary and grammar that the students have, which is a basic skill in Japanese learning. However, if we only emphasize the vocabulary and grammar, and neglect the translation ability, it will eventually result in the students' declining ability in Japanese application. What is the purpose of vocabulary and grammar? What is the purpose of learning Japanese? Some teachers and schools have seriously neglected the ultimate purpose of Japanese study, just to meet the requirements of tests. The purpose of Japanese learning is to make students more comfortable with the use of language and to increase the weight of the workplace. In terms of the translation ability of students at this stage, there are fewer and fewer people who can use Japanese easily, which should draw the attention of teachers and schools.

Japanese learning is not easy. Nowadays, the teaching of Japanese still adopts the "cramming" mode, especially for the "Japanese translation" course. The Japanese teacher uses indoctrination teaching method, and the teacher is the master of the whole class, also is the evaluator. Teachers use the previous teaching methods in the classroom, and the students listen mechanically, without giving the time for independent thinking. In many "Japanese Translation" courses, the text is interpreted by the teacher alone and the students listen passively. That is to say, the student's dominant position in the classroom has not been played out, and has not been actively involved in Japanese translation. The teacher assigns some homework to the students, and then the teacher corrects them after the students hand in their assignments. This teaching method is very dull in the application process. There is no communication between the teacher and the students. The students 
themselves do not have time to think about how to translate the Japanese language. The teacher also conveys the skills of translation to the students, but they do not put them into practice. It is impossible to achieve the effect of practice only by doing homework under class. Most students can't digest the skills taught by their teacher in the classroom, so that they will always copy or rely on the professional translation tools to complete their homework, which will have a direct impact on the students' Japanese translation ability. In addition, there is a certain difference between the students. Most teachers do not take this into consideration in the selection of course content, so that the selected course content cannot be accepted by the students. Therefore, it can be seen that ignoring the teaching mode of flipped classroom has caused the students to lose interest in learning Japanese, thus reducing the teaching quality of Japanese translation courses.

\section{Optimization of Flipped Classroom in "Japanese Translation” Course}

The teaching mode of flipped classroom also needs constant reform in the adoption of teaching materials. Our Japanese translation course should be based on the textbook, but it can't be entirely dependent on the textbook. Some textbooks do not follow the development of the times, and some textbooks are very outdated for the selection of articles. Therefore, teachers should teach them pertinently. If the teaching material is news, it is necessary to update it, because only the latest news materials can help the students' brains keep pace with the time, and learn a lot of knowledge. Japanese translation teachers should pay more attention to the selection of teaching materials, and students should study cutting-edge articles on the premise of basic knowledge. In Japanese translation, it's important to update the knowledge, and when translation and society are out of the way, the meaning of the translation cannot be fully realized. In addition, the new material can stimulate students' interest in learning, especially the materials closely related to students, which can not only attract students' interest in learning, but also exercise their translation ability. On top of that, when conditions are available, students can choose the textbooks for the next semester at the end of the term. Only in this way can they better use the flipped classroom and fully arouse students' interest in learning.

For a foreign language of which the students do not have any cognitive knowledge, it's very difficult to learn, so it's very necessary to stimulate the interests of students in learning. All knowledge is very important to lead in the introduction, if there some problems in the introduction part, it is bound to affect the subsequent learning. As far as language is concerned, entry learning is the study of vocabulary. However, many vocabularies are required to be kept in mind, which makes students feel bored, and has an influence on students' interest in Japanese study. Therefore, the promotion of students' interest is the most important in Japanese translation. The students are the masters of the course, and it is the students who are learning the knowledge. Therefore, in the classroom, students should be taken as the main body, and the people-oriented thoughts should be applied in the process of Japanese translation. At the same time, teachers should strengthen the cultivation of students' autonomous ability. The first step is to stimulate their interest in Japanese translation. For beginners in Japanese learning, the appropriate teaching method adopted by the teachers is especially important. Traditional teaching cannot meet the specific needs of modern students in the classroom. Therefore, teachers should use the classroom atmosphere to carry out active learning. It is possible to introduce some Japanese culture and Japanese development to students before the class starts, so as to attract students' attention in class and then choose some small stories related to Japanese. As the Japanese animation industry developed, most students embraced it and enjoyed it. The Japanese translation teacher can seize this opportunity, use the multimedia technology to show some Japanese cartoon video to the students, then ask them questions. It can not only stimulate students' interest in this course, but also enhance their understanding in Japanese translation.

The teaching mode of flipped classroom can improve the level of Japanese translation. At the same time, students will be fully aware of the relevant knowledge of "Japanese translation". Most teachers and students do not pay much attention to the translation of Japanese translation courses. In the classroom, they only give oral narration of the work to be carried out in translation. In this way, 
the students' translation ability will not be improved, and it will also lead to the decline of translation level. The time in the class is restrictive, and the training in the class is also limited, so it's very important that students use their spare time to study and practice. Japanese translation teachers must value their student's Japanese translation skills, allowing students to practice their ability to translate in the dorm or in the library. In the process of watching animation, students can translate the dialogues in the animation. When encountering problems, they should use professional tools to solve the problems by themselves. If they fail to solve them, they can record the problems in detail and consult their teachers. Or a simple test can be organized in class, and students have to work out each other and evaluate their classmate's work give scores. In the flipped classroom teaching mode, students should exchange the completed test paper with other students, then revise and check them, and the teacher should summarize and correct them in general. In this way, it can help students form better thinking mode and improve their translation ability.

\section{Conclusion}

To sum up, "Japanese translation" is very important in Japanese teaching, whether it is the teaching level of Japanese majors or the large demand for Japanese talents, both cannot be separated from the teaching of Japanese translation. The Japanese translation teaching is a powerful way to cultivate applied talents. As for students, in order to improve the level of Japanese translation, we should use the flipped classroom model in class to improve students' learning consciousness in Japanese translation. For teachers, it is necessary to improve their professional quality and arouse students' interest. In the mode of flipped classroom, the teaching quality is improved continuously.

\section{References}

[1] Huang Wei. “Application Research of Flipped Classroom Mode in Japanese Intensive Reading (intermediate) Teaching--Centered on Japanese Sentence Pattern Teaching” [J]. Education Research, 2017(40):77.

[2] Zhou Xiaobing. “Application of Flipped Classroom Mode in Comprehensive Japanese Teaching in Universities” [J]. Literature and Education Materials, 2017(24): 237-238.

[3] Qi Haijuan. “Study on the Teaching Mode of Japanese Professional Culture Courses Based on the Concept of Flipped Classroom -- Taking the Sino-Japanese Cultural Comparison Course as an Example” [J]. Literature and Education Materials, 2017(23):181-182.

[4] Li Jiao. “Application of Micro-course in Japanese Teaching in Colleges and Universities” [J]. Forestry Teaching, 2016(11):50-52. 